\title{
QUESTÕES ACERCA DO DIAGNÓSTICO DA DEPRESSÃO E SUA RELAÇÃO COM O CAMPO MÉDICO E CIENTÍFICO
}

\author{
Issues about the depression diagnosis and its relation to the medical and scientific field
}

\author{
Rogerio Robbe Quintella
}

Professor de Psicologia da Faculdade Universo (Niterói), Mestre e Doutor em Teoria Psicanalítica pela Universidade Federal do Rio de Janeiro (UFRJ), Niterói, RJ - Brasil, e-mail: rrquintella@hotmail.com

\begin{abstract}
Resumo
Este trabalho visa a discutir, numa perspectiva crítica, alguns dos problemas relacionados ao diagnóstico psiquiátrico da depressão e suas implicações no campo médico e científico. Busca-se demonstrar que os últimos Manuais Psiquiátricos (CID-10 e DSM-IV) diluem importantes manifestações clínicas, como a melancolia, no diagnóstico da depressão; por outro lado, conforme se pode observar nos próprios Manuais, os sintomas dessa última entrecruzam-se com quase todas as outras psicopatologias. Verifica-se ali que a depressão se acha presente em um número extremado de transtornos, de maneira muito mais acentuada do que na relação cruzada de outras patologias entre si. Essas verificações levam a questionar o destaque dado à depressão nas classificações atuais, bem como sua prevalência no âmbito do diagnóstico médico. A apreensão do universo depressivo nos últimos Manuais revela um amplo procedimento que parte das pesquisas neuroquímicas para a distribuição nosográfica dos Transtornos Depressivos, o que se acha intimamente relacionado à psiquiatria biológica. Demonstra-se a precariedade dessa apreensão a partir da própria dificuldade de sustentação do pressuposto fisiopatológico da depressão, posto que as pesquisas nessa área não apontam de maneira definitiva uma relação de causalidade entre as alterações químicas e os sintomas depressivos. A inexistência de marcadores irrefutáveis para o pressuposto fisiopatológico da depressão leva-nos a questionar seu tratamento eminentemente químico. Por fim, procura-se discutir as implicações do discurso médico e científico no universo subjetivo, propondo que, associados ao campo midiático, esses discursos tendem a separar cada vez mais a patologia depressiva do universo subjetivo e mesmo cultural no qual ela se insere.
\end{abstract}

Palavras-chave: Depressão. Diagnóstico. Psiquiatria. Subjetividade. 


\begin{abstract}
This paper aims to discuss, under a critical perspective, some of the problems related to psychiatric diagnosis of depression and its implications in medical and scientific field. We try to demonstrate that the last Psychiatric Manuals (ICD-10 and DSM-IV) dilute important clinical manifestations, such as melancholy, in the diagnosis of depression; on the other hand, as it can be observed in the manuals itself, the symptoms of the latter tie up with almost all other psychopathologies. It is there that depression is present in an extreme number of disorders, much more accentuated than in the crossed relation of other diseases to each other. These verifications lead us to question the prominence given to depression in the current classifications, and its prevalence within the medical diagnosis. The apprehension of the depressive universe in the last Manuals reveals a large procedure that comes from neurochemical researches for the nosographic distribution of the Depressive Disorders, which is closely related to biological psychiatry. It is shown the precariousness of this apprehension from the very difficulty of sustaining the pathogenesis assumption of depression, since the researches on that area do not point permanently a relation of causality between the chemical changes and the depressive symptoms. The absence of irrefutable markers to the pathophysiological assumption of depression leads us to question its very chemical treatment. Finally, we aimed to discuss the implications of medical and scientific speech in the subjective universe, proposing that, associated with the media field, those speeches tend to separate each time more the depressive pathology from the subjective and even cultural universe in which it's inserted.
\end{abstract}

Keywords: Depression. Diagnosis. Psychiatry. Subjectivity.

\section{INTRODUÇÃO}

O tema da depressão é hoje difundido pelos dispositivos de mídia, bem como pelo discurso médico, de maneira articulada por premissas e concepções biologizantes. Os aspectos patológicos da depressão acham-se, sob tal concepção, no domínio do último, donde se conclama um olhar biologicista, lançado como porta-voz de concepção vitimizadora pela condição de Transtorno, na qual a depressão é colocada, sendo o "indivíduo deprimido" o ponto de incidência do acometimento em questão. A depressão é entendida como um "mal", tão ao gosto da farmacologia, que, pautada no cientificismo, não inclui a dimensão psíquica configurada pelo enredo histórico que marca o sujeito em sua subjetivação e em seu posicionamento perante o outro e o mundo, como situam determinadas correntes na psicologia, como, por exemplo, a fenomenologia e a psicanálise.

O presente trabalho tem por objetivo discutir, numa perspectiva crítica, alguns dos problemas relacionados ao diagnóstico psiquiátrico da depressão mediante uma análise sobre a construção dos últimos Manuais de psiquiatria ${ }^{1}$ e suas implicações no campo médico e científico. Essa apreensão pode oferecer elementos importantes para uma discussão sobre o lugar da subjetividade no universo depressivo, dado que, como veremos, esse aspecto se acha excluído da apreensão psiquiátrica, a qual opera, hegemonicamente, uma difusão do conceito de depressão tendente ao reducionismo biológico. Como será visto aqui, existem questões sobre a própria construção dos últimos Manuais que, a nosso ver, merecem reflexão aprofundada, o que se buscará fazer a partir do exame pormenorizado da nosografia depressiva nesses Manuais.

\section{DESENVOLVIMENTO}

Nos manuais de psiquiatria, a classificação das manifestações depressivas contém aspectos os mais variados, desde quadros leves,

DSM-IV e CID-10. 
severos ou isolados, até situações nas quais os sintomas depressivos aparecem associados a outros transtornos - o que se observa na maioria dos casos. Por outro lado, como veremos adiante, pode-se constatar na construção dos últimos Manuais psiquiátricos uma clara diluição da patologia melancólica no diagnóstico depressivo, o que pode surgir como um primeiro elemento problemático, à medida que esse último passa a tomar corpo, abarcando marcadores que anteriormente apareciam de maneira separada nos Manuais. Tomando esse assunto como o ponto inicial dessa investigação, questiona-se os parâmetros envolvidos nas inferências diagnósticas baseadas nos últimos Manuais. Para isso, este artigo se volta ao estudo da nosografia depressiva, de acordo com o desenvolvimento que se segue.

\section{O diagnóstico da depressão no campo psiquiátrico}

O movimento psiquiátrico de circunscrição diagnóstica preconiza que as linhas lógicas de seu delineamento devem ser desenvolvidas sob o ponto de vista de uma apreensão descritiva pura, sem o estabelecimento de pressupostos teóricos. Ao se buscar a distribuição nosográfica desenvolvida pela psiquiatria concernente aos quadros depressivos, pode-se perceber que sua delimitação se concentra nos chamados Transtornos do Humor. No DSM-IV, tal classificação subdivide-se em Transtornos Depressivos, Episódios Depressivos, Transtorno Distímico, Transtorno Ciclotímico, Transtorno Bipolar I e II; no CID-10, subdivide-se em Transtorno Afetivo Bipolar, Transtorno Depressivo Recorrente, Episódios Depressivos e Transtorno Persistente do Humor (ciclotimia e distimia).

Essas classificações entrecruzam-se nas descrições nosográficas, como se pode observar nas relações entre o Transtorno Depressivo Maior, o Episódio Depressivo Maior e o Transtorno Distímico no DSM-IV. Vejamos, pois, como aparece a distribuição nosográfica da depressão no DSM-IV.

\section{DSM-IV}

Os chamados Transtornos de Humor têm como uma das mais importantes referências aquilo que na distribuição nosográfica é denominado Transtorno Depressivo Maior. Essa denominação, que compõe a classificação dos Transtornos Depressivos, é um quadro caracterizado por um ou mais Episódios Depressivos Maiores, sem história de Episódios Maníacos, Mistos ou Hipomaníacos. Os Transtornos Depressivos, segundo o DSM-IV, devem ser diagnosticados na ausência desses três últimos fatores, ou seja, caso um ou mais deles apareçam intercorrentemente num Transtorno Depressivo Maior, sem interferência de substâncias antidepressivas ou uso de medicamentos e exposição a toxinas, o diagnóstico deverá ser transferido para Transtorno Bipolar.

Os Episódios Depressivos Maiores, que compõem o Transtorno Depressivo Maior, definemse como episódios de humor deprimido ou perda de interesse e prazer por quase todas as atividades; alterações no apetite ou peso, sono e atividade psicomotora; diminuição da energia; sentimentos de desvalia ou culpa; dificuldade para pensar, concentrarse ou tomar decisões, ou pensamentos recorrentes sobre morte ou ideação suicida, planos ou tentativas de suicídio. Distorção na interpretação de eventos triviais é comum nesses quadros, com senso exagerado de responsabilidade pelas adversidades. Dentre essas características, o sentimento de desvalia ou culpa nas descrições do DSM-IV pode assumir proporções delirantes (por exemplo, convicção de ser pessoalmente responsável pela pobreza que há no mundo). O denominado Episódio Depressivo Maior deve apresentar também prejuízo clinicamente significativo no funcionamento social, profissional ou em outras áreas importantes da vida do indivíduo. Devem ser classificados, segundo o DSM-IV como leve, moderado, severo sem aspectos psicóticos, severo com aspectos psicóticos, em remissão parcial, ou em remissão completa. Um Episódio Depressivo Maior pode ser classificado também como crônico, com características catatônicas, com características melancólicas, com características atípicas, ou com início no pós-parto.

O Transtorno Distímico, por sua vez, diferencia-se do Transtorno Depressivo Maior ou de um Episódio Depressivo Maior no DSM-IV pelos aspectos gerais de gravidade, cronicidade e persistência. Seu humor é descrito como triste ou "na fossa" e, enquanto que um Episódio Depressivo Maior é diagnosticado na presença de sintomas depressivos de um período mínimo de duas semanas consecutivas, o Transtorno Distímico representa a 
presença de sintomas com prevalência de no mínimo dois anos, com sintomas adicionais de apetite diminuído ou hiperfagia, insônia ou hipersonia, baixa energia ou fadiga, baixa auto-estima, fraca concentração ou dificuldade em tomar decisões e sentimentos de desesperança. O diagnóstico diferencial entre esses dois tipos de transtornos na classificação psiquiátrica aparece no DSM-IV como de difícil composição. O diagnóstico de Transtorno Distímico pode apenas ser implementado se, no período de dois anos referentes a um quadro de distimia, não houve nenhum Episódio Depressivo Maior. Esses são caracterizados por uma frequente variação no estado de humor habitual do indivíduo, ao passo que o Transtorno Distímico caracteriza-se por sintomas depressivos crônicos e menos severos, presentes por muitos anos, sem grandes variações no estado de humor do sujeito nesse período. Dito de outra forma, o Transtorno Distímico caracterizase por um humor depressivo de longa duração, sem grandes variações e menos severo. No Transtorno Depressivo Maior (que inclui Episódios Depressivos Maiores), o quadro caracteriza-se como uma alta variação no estado de humor, em períodos curtos. No que se refere ao Transtorno Ciclotímico, nele se encontram sintomas hipomaníacos em determinados períodos e sintomas depressivos em outros. Os sintomas hipomaníacos, por sua vez, apresentam as mesmas características do Transtorno Maníaco, com exceção das atividades delirantes ou alucinatórias, as quais aparecem nesse último, mas estão ausentes em um Episódio Hipomaníaco. Na Ciclotimia, os sintomas depressivos não correspondem ao grau de abrangência ou duração suficientes para a classificação de Transtorno Depressivo Maior.

O Transtorno Bipolar (I e II), que se apresenta também como uma das classificações relativas aos chamados Transtornos de Humor, inclui quadros depressivos, especialmente o Transtorno Bipolar II. Esse se estabelece no DSMIV pela presença de um ou mais Episódios Depressivos Maiores, acompanhados por pelo menos um Episódio Hipomaníaco. O Transtorno Bipolar I é caracterizado pela ocorrência de um ou mais Episódios Maníacos ou Episódios Mistos (nos quais se satisfazem critérios tanto para Episódio Maníaco quanto para Episódio Depressivo Maior).
O DSM-IV inclui caracterizações que se diferenciam do CID-10 em algumas nomenclaturas, mas, em geral, apresentam especificações extremamente similares às do último, sem grandes variações no modo de distribuição. Vejamos, pois, como isso aparece no CID-10.

\section{CID-10}

Como foi dito, no CID-10 os Transtornos do Humor subdividem-se em Transtorno Afetivo Bipolar, Transtorno Persistente do Humor (ciclotimia e distimia), Episódios Depressivos e Transtorno Depressivo Recorrente, sendo que esses três últimos concentram uma caracterização mais isolada do quadro depressivo.

Os Episódios Depressivos são caracterizados pelo CID-10 como estados de rebaixamento do humor, redução da energia e diminuição da atividade. A perda de interesse, a diminuição da capacidade de concentração, fadiga mesmo após um esforço mínimo, problemas do sono e diminuição do apetite são os sintomas principais dos Episódios Depressivos. Também são inseridos nessa classificação sintomas como diminuição da auto-estima e da autoconfiança e ideias de culpabilidade e ou de indignidade, mesmo nas formas leves. Segundo este Manual, o humor depressivo pode acompanhar um despertar matinal precoce, várias horas antes da hora habitual de despertar, agravamento matinal da depressão, lentidão psicomotora importante, agitação, perda de apetite, perda de peso e perda da libido. São classificados como leve, moderado ou grave - sendo que esse último quesito pode ou não vir acompanhado de sintomas psicóticos. ${ }^{2}$

Os Episódios Depressivos são delineados de acordo com a gravidade com que aparecem os sintomas. Nos Episódios Depressivos inclui-se uma categoria chamada "reação depressiva", não especificada no CID-10, mas que, conforme se pode depreender de sua nomenclatura, surge como reação a fatores psicossociais inespecíficos.

O denominado Transtorno Depressivo Recorrente (CID-10) é caracterizado por ocorrência repetida de episódios depressivos, comportando possivelmente breves episódios caracterizados por uma ligeira exaltação do humor e da atividade

\footnotetext{
2 Episódio Depressivo Leve, Episódio Depressivo Moderado, Episódio Depressivo Grave sem sintomas psicóticos, Episódio Depressivo Grave com sintomas psicóticos (Organização Mundial de Saúde, CID-10, 1996-1997).
} 
(hipomania), sucedendo imediatamente um episódio depressivo. Apresentam, segundo o CID10, "numerosos pontos comuns com os conceitos da depressão maníaco-depressiva, melancolia, depressão vital e depressão endógena”. Em caso de ocorrência de um episódio maníaco, o diagnóstico deve ser alterado pelo de Transtorno Afetivo Bipolar, mas o risco de ocorrência de um episódio maníaco não pode jamais ser completamente descartado em um paciente com um Transtorno Depressivo Recorrente, qualquer que seja o número de episódios depressivos apresentados. Também pode uma "reação depressiva" ser, conforme o Manual, caracterizada como Transtorno Depressivo Recorrente.

O Transtorno Persistente do Humor é um conjunto de sintomas persistentes e habitualmente flutuantes, nos quais os episódios individuais não são suficientemente graves para justificar um diagnóstico de Episódio Maníaco ou de Episódio Depressivo Leve. Como persistem por anos e, às vezes, durante a maior parte da vida adulta do paciente, levam a um sofrimento e incapacidade consideráveis. Em certos casos, episódios maníacos ou depressivos recorrentes ou isolados podem se superpor a um transtorno afetivo persistente.

Ciclotimia e Distimia são as duas principais categorias do Transtorno Persistente do Humor, sendo a primeira caracterizada por:

[...] instabilidade persistente do humor que comporta numerosos períodos de depressão ou deleve elação, nenhum deles suficientemente grave ou prolongado para responder aos critérios de um Transtorno Afetivo Bipolar ou de um Transtorno Depressivo Recorrente [...]. Algumas pessoas ciclotímicas apresentarão elas próprias ulteriormente um transtorno afetivo bipolar (Organização Mundial de Saúde OMS, 1995).

A Distimia no CID-10, por sua vez, é classificada por um "rebaixamento crônico do humor, persistindo ao menos por vários anos, mas cuja gravidade não é suficiente ou na qual os episódios individuais são muito curtos para responder aos critérios de transtorno depressivo recorrente grave, moderado ou leve".

No CID-10, a distribuição dos Transtornos de Humor passa também pela classificação dos Transtornos Afetivos Bipolares, nos quais a depressão aparece associada ao que se denomina
Psicose Maníaco-Depressiva (na qual aparece a mania com sintomas psicóticos). Os Transtornos Afetivos Bipolares são caracterizados por um nível de atividade profundamente perturbada, sendo que esse distúrbio consiste em elevação do humor e aumento da energia e da atividade (hipomania ou mania) em algumas ocasiões, e em outras, em rebaixamento do humor e redução da energia e da atividade (depressão).

Apesar de se concentrarem nos chamados Transtornos do Humor, os sintomas depressivos fazem-se verificar em diversas outras classificações nosográficas, podendo seridentificados de maneira imbricada com tantas outras patologias. Como se constata, por exemplo, através da caracterização presente na classificação dos Transtornos Alimentares (DSM-IV), a anorexia nervosa contém, na grande parte dos casos, fortes sintomas de depressão. Tal sintomatologia satisfaz as exigências para a classificação de Transtorno Depressivo Maior, ou mesmo um Transtorno Distímico. No CID-10, a Depressão Ansiosa Persistente apresenta sintomas de depressão na distimia intimamente associados à ansiedade crônica. No mesmo Manual encontramos uma categoria de transtorno ansioso caracterizada por Transtorno Misto Ansioso e Depressivo. O indivíduo apresenta ao mesmo tempo sintomas ansiosos e depressivos, sem predominância nítida de uns ou de outros, e sem que a intensidade de uns ou de outros seja suficiente para justificar um diagnóstico isolado.

Tanto no CID-10 como no DSM-IV, esses transtornos depressivos ou os sintomas diversos que lhes correspondem associam-se frequentemente a muitos outros: observando o DSM-IV em sua totalidade, verificam-se sintomas ou transtornos depressivos presentes no Transtorno ObsessivoCompulsivo, na Anorexia Nervosa, na Bulimia Nervosa, no Transtorno de Pânico, no denominado Transtorno do Ajustamento, nos Transtornos de Ansiedade, nos Transtornos Psicóticos, na Esquizofrenia, na Tricotilomania, no Transtorno Ciclotímico, no Transtorno Bipolar, no Transtorno de Estresse Agudo, na Cleptomania, no Transtorno de Aprendizagem, no Transtorno Conversivo, no Transtorno de Somatização, no denominado Transtorno Doloroso, no Transtorno de Sonambulismo, nos Transtornos do Sono, na Agorafobia, na Narcolepsia, na Fobia Social, no Transtorno Dismórfico Corporal, nos Transtornos de Ansiedade em geral, em todos os Transtornos de 
Personalidade.

Sendo tal enfoque extremamente importante para uma análise das configurações classificatórias na distribuição nosográfica, os campos de reflexão sobre o destaque dado à depressão se dirigem para uma discussão que parte das apreensões concernentes ao cruzamento dos transtornos como um todo e da relação entre eles e a depressão o que, como se pode observar, estabelece-se de maneira frequente.

\section{Discussão crítica}

Em primeira instância, é necessário que se coloque em discussão determinados contextos problemáticos que aparecem na difusão midiática do tema da depressão em associação com o discurso médico-científico. Para tanto, partimos do próprio delineamento psiquiátrico no âmbito das classificações nosográficas. Conforme pudemos constatar, no DSM-IV e no CID-10 existem inúmeras referências a quadros depressivos, desde os mais isolados e severos, até aqueles que se acham imbricados com outros indicadores patológicos. Ao verificarmos as classificações da depressão, identificamos enquadres nosográficos e indicadores estatísticos que suscitam para nós importante questão. Nesse sentido, apontamos:

1. Aquilo que se denomina Transtorno Depressivo Sem Outra Especificação (DSM-IV), definido como "[...] transtornos com características depressivas que não satisfazem os critérios para Transtorno Depressivo Maior, Transtorno Distímico, Transtorno de Ajustamento com Humor Deprimido ou Transtorno de Ajustamento Misto de Ansiedade e Depressão", refere-se a um quadro que poderia ser tomado, por exemplo, como uma "reação depressiva" qualquer, sem maiores indicadores crônicos ou agudos (a "reação depressiva" é identificada no CID-10 como uma das categorias dos chamados Episódios Depressivos). Tal conjuntura é, contudo, incluída também sob a categoria de Transtorno, mesmo que Sem Outra Especificação.

2. Verifica-se nas estatísticas do próprio DSM-IV que $40 \%$ das pessoas diagnosticadas com Transtorno Depressivo Maior não apresentam, após um estudo mais detido e rigoroso em cada caso, qualquer motivo para um diagnóstico propriamente dito de Transtorno de Humor, segundo o próprio Manual ${ }^{3}$. Ou seja, o chamado Episódio Depressivo, que inclui a designação Transtorno Depressivo Maior - Episódio Único, ou Transtorno Depressivo Sem Outra Especificação, pode levar a um diagnóstico que inclua o indivíduo como portador de Transtorno Depressivo. Mesmo que de curto período, tal "transtorno" acaba por ser tratado e medicado como tal, ainda que não confirmado como patologia crônica e perene (Transtorno de Humor) no transcorrer do tempo ${ }^{4}$.

3. Constata-se também, a partir de verificações em manuais anteriores, que a classificação da depressão tomou corpo e atingiu de maneira crescente designações específicas e isoladas nos Manuais mais recentes, nos quais se encontra vasta subdivisão dos Transtornos de Humorem quadros depressivos isolados. Nos manuais anteriores ao DSM-III e IV, as designações relativas aos Transtornos Ciclotímicos e Distímicos não existiam. Quadros relacionados a sintomas depressivos encontravam-se distribuídos em outras patologias, como Psicose ManíacoDepressiva, Melancolia de Involução (CID-06), Psicoses Afetivas (CID-09), ${ }^{5}$

\footnotetext{
3 No DSM-IV (Associação de Psiquiatria Americana-APA, 1995), tal indicador aparece da seguinte forma: "Estudos naturalistas de seguimento sugeriram que, um ano após o diagnóstico de Episódio Depressivo Maior, 40\% dos indivíduos ainda têm sintomas suficientemente severos para satisfazerem os critérios para um Episódio Depressivo Maior completo, aproximadamente 20\% continuam com alguns sintomas que não mais satisfazem todos os critérios para Episódio Depressivo Maior (isto é, Transtorno Depressivo Maior, em Remissão Parcial) e 40\% não têm Transtorno do Humor “ (Grifo do autor).

4 O mesmo se pode verificar a respeito do Transtorno Depressivo Recorrente Sem Especificação, no CID-10.
} 
etc. Tais transtornos (Ciclotímicos e Distímicos) surgiram no DSM-III, com a categoria das Desordens Afetivas, subdivididas ali em quadros depressivos diversos. O destaque dado aos Transtornos Depressivos acirrou-se no DSM-IV e no CID-10, nos quais a melancolia, como pudemos constatar, dissolveu-se definitivamente.

4. Ao fazermos um cruzamento entre as designações para a depressão e as demais definições nosográficas, observamos nessas últimas uma alta incidência de sintomas depressivos. Esse fenômeno - aparecimento de um transtorno na grande maioria dos demais - não se faz notar com essa veemência quando feito o mesmo cruzamento entre outras patologias. OTranstorno Obsessivo-Compulsivo, por exemplo, aparece também nos Transtornos de Ansiedade, nos Transtornos Alimentares e no Transtorno de Tourette, mas não é localizado em mais nenhuma outra patologia, permanecendo restrito a tais enquadres. Verifica-se que a depressão se acha presente em um número extremado de transtornos - quase todos -, de maneira muito mais acentuada que na relação cruzada de outras patologias entre si.

$\mathrm{O}$ que se problematiza aqui com esses apontamentos é um conjunto de fatores do campo médico-científico deflagradores de um movimento - apreendido a partir da análise da própria classificação psiquiátrica da depressão - que leva a uma priorização do diagnóstico de depressão em casos diversos. Como se apontou acima, 40\% das pessoas diagnosticadas como deprimidas (Episódio Depressivo) não são posteriormente diagnosticadas com Transtorno de Humor numa investigação mais apurada. Ou seja, esses pacientes, apesar de não apresentarem uma patologia crônica, são também diagnosticados e tratados sob a denominação de Transtorno Depressivo Maior, mesmo que "de Episódio Único" - se feita uma observação posterior mais detida (ou sob a denominação de Transtorno Depressivo Sem Outra Especificação).

Nesse âmbito, colocam-se em questão dois pontos problemáticos presentes nos Manuais. O primeiro deles é o cruzamento de fenômenos depressivos com quase todas as outras patologias; o segundo ponto refere-se à vaga distinção entre fenômenos depressivos e fenômenos melancólicos. Pergunta-se, sob esse contexto: o que motiva, no campo psiquiátrico, uma proeminência tão veemente da classificação da depressão nos últimos Manuais, categorizando-a como transtorno circunscrito? Por que diluir a melancolia na depressão, já que a primeira encontrava-se destacada como patologia específica nos Manuais anteriores? Está presente apenas uma apreensão empirista em tais classificações? Afora o inegável aumento nas últimas décadas de pacientes que procuram tratamento apresentando a preponderância clínica de sintomas depressivos, haveria um movimento diretivo por parte dos dispositivos médicos para o diagnóstico de depressão? Que fatores foram decisivos para a constituição dos Manuais mais recentes? Que elementos poderiam nos servir de parâmetro para uma análise mais aprofundada dessas questões que nos leve a uma resposta a respeito da relação entre tais definições e os contextos nos quais elas são constituídas?

Os problemas referentes a tais indagações podem ser visualizados a partir do momento em que se considera a existência de vetores que ultrapassam a pura observação empírica e que, ao mesmo tempo, atravessam a construção dos conceitos - incluindose aí concepções sobre transtorno, doença, depressão, subjetividade etc. Considera-se sob esse aspecto que tais vetores acham-se condicionados por questões de concepção. Caberia indagar que dispositivo de intervenção e tratamento toma destaque privilegiado sob essa configuração.

Bogochvol (2001) assinala que a medicina serve-se preponderantemente da farmacologia, aplicando terapia de pressupostos biológicos e neuroquímicos. Inscreve-se nessa condição a possibilidade ou não de indicação, em um caso ou em outro, de um procedimento psicoterápico “de apoio”, ou "associado" - geralmente a psicoterapia cognitivocomportamental como elemento coadjuvante ao tratamento químico (Ehrenberg, 1998). Nessa concepção, identificam-se dois pressupostos de base

\footnotetext{
5 Organização Mundial de Saúde, CID-06, 1948; Organização Mundial de Saúde, CID-09, 1978.
} 
para a explicação fisiológica ou genética da depressão (seja ela melancólica ou não). Um pressuposto defende que sua causa fundamental encontra-se na diminuição do neurotransmissor denominado noradrenalina, outro aponta a diminuição da serotonina como base funcional da depressão (Ballone, 2007). Tais pressupostos apoiam-se nos estudos das alterações neuroquímicas em que os chamados Transtornos Depressivos se manifestam.

Faz-se necessário frisar, contudo, que os próprios pressupostos neuroquímicos não apresentaram até hoje a consistência esperada para sua positivação, permanecendo ainda tal perspectiva alicerçada em hipóteses e indicativos incertos, conforme encontramos na seguinte fonte de informação:

Outro achado que suscitava dúvidas sobre a causa exclusiva da hipofunção de neurotransmissores, foi que a deficiência de noradrenalina e/ou de serotonina, assim como de seus metabólitos no líquido cefalorraquidiano (LCR), no sangue ou na urina, nunca foi consistentemente demonstrada em pacientes depressivos, apesar dos múltiplos esforços nesse sentido. Os trabalhos que atestavam eventual deficiência de catecolaminas e metabólitos em pacientes deprimidos não eram confirmados por outros estudos (Ballone, 2007, p. 5).

Rodrigues (2000, p. 162), por sua vez, não deixa de frisar a precariedade da premissa fisiopatológica para a explicação dos Transtornos Depressivos e para a legitimação de uma terapia eminentemente química pautada em pressupostos biologizantes. Nesse sentido, afirma:

[...] nenhum dos dois neurotransmissores pode ser utilizado como um marcador biológico seguro, uma vez que a alteração não é nem constante e nem sempre envolve o mesmo neurotransmissor. Não faltaram tentativas de se buscarem outros marcadores biológicos (teste de Dexametasona, marcadores fisiológicos, endocrinológicos, etc.), mas nenhum deles mostrou-se suficientemente específico e sensível para esse transtorno.

A Teoria das Monoaminas (Wikipédia, 2008), base da perspectiva investigativa pautada no pressuposto fisiopatológico, afirma que a depressão crônica ou profunda poderá apresentar pequenas diminuições na utilização dos neurotransmissores monoaminas (noradrenalina e dopamina) e da serotonina. Os antidepressivos agiriam na inibição da recaptação da serotonina ou da noradrenalina.

Nessas apreensões subjazem correlações entre estados definidos como depressivos e alterações neuroquímicas que constituiriam, sob esse contexto, a base da concepção fisiopatológica. A análise mais minuciosa acerca dos achados bioquímicos e farmacológicos revela, contudo, alguns problemas na concepção fisiopatológica que derivam da aplicação nem sempre bem-sucedida dessas substâncias. Tais problemas decorrem também dos pressupostos não confirmados com exatidão quando da investigação aprofundada sobre tais alterações fisiológicas. Esse campo investigativo não apresenta positivação da conjuntura específica em termos de previsibilidade, controle e certeza.

[...] na depressão unipolar, mesmo profunda, na maioria das vezes não há alterações, e na depressão unipolar moderada estas diminuições, quando existem, não são significativas. Contudo, todos os fármacos eficazes no tratamento da depressão aumentam os níveis de alguns desses neurotransmissores. É sabido que a dopamina éimportante nas vias da satisfação, e a adrenalina e serotonina produzem efeitos de satisfação (Wikipédia, 2008, p. 1).

Fica claro que não é a alteração fisiológica em si o que justifica a utilização do fármaco, mas seus efeitos posteriores. Como se constata, não há ali indícios claros de uma etiopatogenia química no sofrimento depressivo.

Outra linha de frente que se pauta na busca pela explicação fisiopatológica dos estados depressivos norteia atualmente, de maneira mais preponderante, as pesquisas relacionadas a esse campo psicopatológico. Essas pesquisas apontam hipóteses relacionadas a neuroreceptores, mais do que neurotransmissores, apesar de também não terem sido confirmadas essas hipóteses no campo científico.

[...] as hipóteses da desregulação no número e na sensibilidade do neuroreceptor sugerem que, em síntese, as deficiências funcionais na neurotransmissão podem ocorrer mesmo com níveis normais de neurotransmissores, e não têm sido conclusivos os estudos para identificar 
uma clara evidência entre as deficiências catecolaminas e indolaminas nos pacientes depressivos (Ballone, 2007, p. 5).

Como se pode constatar, a tentativa de se circunscrever etiopatologia depressiva no campo bioquímico não encontrou confirmação que sustente tal concepção de maneira definitiva. Sobre isso, Rodrigues (2000, p. 162) assinala: "[...] ainda que existam alterações bioquímicas na depressão, como a diminuição de certos neurotransmissores, estas não se confundem com sua causa." A existência de alterações bioquímicas no fenômeno depressivo não constitui base suficiente para a sustentação do pressuposto fisiopatológico que explique isoladamente esses transtornos em termos etiológicos. Os próprios Manuais classificam a depressão como transtorno. Não podem classificá-la como doença, dado que não há definição de etiologia fisiopatológica específica que a caracterize como tal. Esse apontamento problematiza dois pontos fundamentais a respeito do diagnóstico psiquiátrico: o enquadre de transtorno dado à depressão, e, na outra ponta do mesmo fio, contraditoriamente, a terapia preponderantemente química, aplicada com base em pressupostos fisiopatológicos.

Sonenreich (1991, p. 2) aponta nesse âmbito a existência de interesse por parte da medicina no desenvolvimento da quimioterapia, o que estaria na base, pois, das novas formulações nosográficas, especialmente aquelas relativas ao DSM-III e IV, bem como às CID-9 e 10:

Com certeza, tal procedimento foi sustentado pelo interesse despertado pela terapia com carbonato de lítio, ganhando amplo uso o conceito de desordens afetivas. Grupos de trabalhos, sessões clínicas e de laboratório, revistas, publicações, dedicam-se especificamente a atividades ligadas a este conceito [“desordens afetivas”] e o usam para definir-se, nomear-se.

O movimento relacionado ao diagnóstico depressivo toma corpo a partir da lógica fisiopatogênica, o que é também discutido por Ehrenberg (1998). O autor situa, nesse ínterim, o surgimento de novas substâncias que agem sobre a ansiedade, a depressão e praticamente todos os sofrimentos e disfunções mentais.

Ehrenberg problematiza essa conjuntura, apontando que as substâncias químicas são também utilizadas em casos não tão graves, na contrapartida de casos crônicos, embora refratários a tais procedimentos. É o que faz sobrevir no próprio campo médico uma crise sobre a ideia de cura, posto que os antidepressivos muitas vezes não incidem da maneira esperada. Conforme se constatou - e o autor aponta -, 50\% dos pacientes recaem depois de um episódio depressivo, 20\% pioram e $15 \%$ a $20 \%$ não passam de remissões de sintomas. A maior parte dos pacientes recai ou varia o seu estado crônico, o que inclui a questão da cronicidade muitas vezes prevalecente dentro da linha química de tratamento. $\mathrm{O}$ autor discute em sua obra sobre a eficácia dos antidepressivos, o que os restringe a um estatuto de melhora e não de cura. A melhora passa então a ser colocada como um marcador importante nesses tratamentos. O autor afirma também que a eficácia do antidepressivo vai depender de cada caso. Em alguns casos observa-se eficácia total; em outros se vê resultado apenas depois de certo tempo. Esses critérios muitas vezes levam em consideração muito mais a intuição clínica do que concepções standardizadas e préestabelecidas, o que abre contradições severas no que tange ao reducionismo bioquímico na direção do tratamento da depressão.

Soma-se a isso a legitimação de práticas que se afirmam como imparciais ou puristas por meio de classificações nosográficas, atravessadas, entretanto, por vetores não restritos ao campo puramente descritivo. A medicina psiquiátrica pauta-se na prerrogativa de que a classificação dos quadros patológicos é desenvolvida com pretensões "ateóricas", restritas fundamentalmente à pura observação e análise descritiva dos fenômenos psicopatológicos. Nessa via, as classificações teriam por objetivo servir à intervenção médica positiva, o que reiteraria o seu valor de utilidade e operação. De fato, os Manuais, em sua estrutura, não apresentam as possíveis implicações etiológicas nos diversos transtornos ${ }^{6}$ (aqui enfocando os depressivos), e a descrição classificatória, como

\footnotetext{
6 A única exceção que se apresenta em termos de etiologia nos Manuais aparece nos chamados Transtornos de Humor Devido a uma Condição Médica e Transtornos de Humor induzidos por Substância, em que se definem marcadores causais, seja por uma "condição médica" qualquer, seja pela introdução de alguma substância que altere o estado psíquico do indivíduo.
} 
dissemos, tentaria seguir uma linha descritiva pura, sem relação com pressupostos teóricos.

Contudo, a existência de fatores carregados de premissas teóricas inexoravelmente presentes nessa operação é ponto que não pode deixar de ser considerado. Nesse traçado lógico, Bogochvol (2001, p. 45) aponta que as concepções químicas "[...] nortearam grande parte da organização das nosografias contemporâneas (o CID-10 e o DSM-IV), que, ironicamente, são apresentadas como ateóricas, denegando, assim, seus próprios pressupostos".

Visamos a sustentar nesse âmbito que a medicina psiquiátrica, ao construir os Manuais, não escapa da presença do observador, o qual, segundo uma análise mais rigorosa, é atravessado por sua doutrina e seu instrumental (Sonenreich, 1991). Ou seja, por mais que uma nosografia purista busque alcançar existência legítima, ela cai inevitavelmente em engrenagens teóricas e até mesmo ideológicas. ${ }^{7}$

Essas considerações, que colocam em questão o caráter meramente observacional da medicina na definição noso-gráfica da depressão, relaciona-se ao contexto não menos problemático daquilo que Clavreul (1983, p. 47) denomina Ordem Médica - terreno por excelência do discurso médico a partir do qual se podem identificar questões de princípio. A Ordem Médica, cujo campo de intervenção alinha-se terminantemente ao olhar objetivante da ciência, não leva em consideração a subjetividade implicada no contexto da clínica médica. O pensamento de J. Clavreul denuncia a presença de uma ideologia própria da prática médica, cujo paradigma esbarra em problemática crucial ao confrontarmos tal prática com a dimensão subjetiva que atravessa a condição humana, seja na esfera do sofrimento físico, seja nos momentos não menos críticos do sofrimento psíquico. Clavreul discute sobre as incidências do discurso médico no campo do sujeito, quando de sua intervenção. $\mathrm{O}$ autor sublinha:

Pois é verdade que a medicina nunca fala da morte, a não ser para tentar adiar sua data de vencimento; ela não fala nunca da vida e do gozo, a não ser para regulamentá-los; ela nega qualquer outra razão de viver que não seja a razão médica que faz viver, eventualmente à força. Mas ela, pelo menos, tem contas a prestar com seus administrados.

Clavreul (1983, p. 40) salienta o caráter totalizador da medicina que, por seus emblemas ordenadores, compõe uma conjuntura inalienável sob a qual a pessoa do médico se acha inexoravelmente inserida. A Ordem Médica encontra-se na superfície da ação médica, e "os médicos são seus executantes, seus funcionários, muitas vezes humildes, às vezes gloriosos, mas a Ordem Médica se impõe por ela mesma”.

Tal totalização deflagra aí o locus de operação do discurso médico. Para Clavreul (1983, p. 48), o poder do discurso médico, alicerçado em seu saber supostamente irrevogável, é o que constitui seu caráter totalitário. A ação médica se acha, sob o olhar instigante de Clavreul, atravessada pela sua palavra de Ordem, no próprio momento em que nós mesmos nos achamos impelidos à adesão àquele que, por seu "saber", detém por momentos a chave da vida (orgânica).

Cada um de nós é seduzido, conquistado, menos por seus resultados terapêuticos que pela extensão e certezas do saber médico, e menos por estas que pela permanência de sua ordem no momento em que o nosso próprio corpo nos abandona. Mas também a medicina

\footnotetext{
É preciso frisar que não se desconsidera, nesta análise, o indiscutível aumento no número de pacientes que demandam tratamento por fatores clínicos cujo traçado aponta para sintomas depressivos, o que se faz notar nos últimos tempos de maneira mais preponderante, tanto nos institutos de saúde quanto nos consultórios privados. Questiona-se, entretanto, a proeminência de um movimento classificatório que dilui no diagnóstico depressivo outras especificações importantes como a melancolia. Também não se sugere, com isso, que a medicina não deva se valer da intervenção química em determinados quadros cuja cronicidade alcança níveis insustentáveis de suportabilidade. O que se problematiza sobre isso é a utilização da psicofarmacologia na legitimação do reducionismo biologizante para a etiologia da depressão, baseada nos efeitos muitas vezes prodigiosos dos medicamentos, bem como nas análises não muito ainda consistentes sobre as alterações neuroquímicas. Conforme pudemos verificar, o índice de pacientes deprimidos não diminuiu nos últimos anos, apesar da incisiva intervenção química, mas aumentou, e 40\% dos pacientes não respondem positivamente à quimioterapia, sendo que, após um ano de interrupção do tratamento, há recaída de 50\% dos pacientes tratados com quimioterapia (Manual diagnóstico e estatístico de transtornos mentais - Episódio Depressivo Maior/DSM-IV, PsiWeb - PSIQUIATRIA GERAL, 1995).
} 
nos reduz ao silêncio. Nenhuma razão é objetável à razão médica, e o médico não recolhe de seu paciente senão o que pode ter lugar no discurso médico. Não se pode pretender salvar ao mesmo tempo o discurso médico e o discurso do paciente.

A objetividade do saber médico substitui, assim, as incertezas do espectro subjetivo, esse pronto desde sempre a aviltar seus ditames quando um elemento (subjetivo) extrínseco ao seu saber e poder de atuação emerge diante de sua visão. Nessa conjuntura, a posição do médico, alicerçada em seu saber, bem como nas ponderações científicas, toma relevo diferenciado quando o médico, diante dos impasses gerados pelas questões fantasmáticas inerentes à própria condição humana, acha-se em posição de pulverizar tal condição - motivo pelo qual Clavreul considera a necessidade de falar da medicina como sendo um discurso. Nesse âmbito, o caráter objetivo de sua prática é tomado pelo autor como uma questão de Ordem, não exatamente detentora ou perseguidora da verdade que lhe competiria, à medida em que faz de seu objeto (a doença) o próprio sujeito de seu discurso, apagando a posição do próprio doente frente ao seu sofrimento.

O discurso médico é aqui tomado, assim, como um dos principais motivos de sua própria formulação questionável, enfatizando-se neste estudo o caráter problemático apresentado acerca da nosografia depressiva. Acredita-se que o problema tem início no próprio movimento que evoca o espírito empirista, mas cujo alcance não se restringe a uma "apreensão" da realidade imune à Ordem Médica e seu totalitarismo-e num plano não menos importante, ao contexto cientificista no qual essa mesma Ordem Médica se insere. Refere-se aqui a contextualidades socioculturais que de certa forma alicerçam e são ao mesmo tempo alicerçadas por esse fenômeno. Como já foi dito, a mídia veicula o tema da depressão de maneira fundamentalmente articulada à discursividade médica, sendo aquele (o tema depressão) difundido como um problema de domínio da última. Assim, o que se inscreve sobre o "indivíduo deprimido" é o "transtorno" que o acomete e vitimiza.

Em contraponto a isso - numa dimensão que ultrapassa a psicopatologia e atinge todo o universo médico -, Sonenreich considera que o que diz respeito ao "doente" é seu sofrimento. A doença não diz respeito ao paciente; ela pertence ao médico. Essa ideia aparece também em Verztman (1994, p. 59), que situa a "doença" como "[...] algo inventado para resolver problemas humanos, antes irrelevantes".

OTranstorno Depressivo-difundido pela mídia como sinônimo de doença - deflagra a conjuntura cultural feita hoje em torno do sofrimento depressivo. Em contrapartida a isso, é importante salientar com Sonenreich que a "doença" - tanto quanto o "transtorno" - contém o sistema de avaliação, conceituação, construção de fronteiras, todos esses elementos sendo delineados pela operação científica e pelo discurso médico nos quais se localiza a separação radical entre patologia depressiva e subjetividade. Nesse âmbito é cumpre infatizar, conforme já assinalamos, que a apropriação do discurso médico por parte da mídia acirra ainda mais tal separação, e o médico, atravessado pela ideologia que abrange seu campo de investigação e intervenção (Ordem Médica), aplica tratamento preponderantemente químico baseado na premissa fisiopatológica - pouco sustentável -, servindo-se na maioria das vezes das chamadas terapias cognitivo-comportamentais, também atravessadas pelo discurso científico. Em todos esses movimentos está a exclusão do sujeito, aquele mesmo resgatado pela psicanálise, tal como aponta Lacan (1985).

No ínterim da questão, podemos concluir que a pretensão purista e empírica da psiquiatria biológica deve ser problematizada quando o que está em questão é a produção do conhecimento. Sobre isso, Rorty (1997, p. 146), referenciado no pensamento pragmático, considera a necessidade de se contextualizar toda produção de ideias relacionadas a uma determinada prática investigativa. Segundo Rorty, qualquer movimento investigativo acha-se inevitavelmente atravessado por contextos presentes na formação da prática científica:

[...] toda investigação é interpretação, todo pensamento é recontextualização. [...] Todos os objetos são, em concordância com a terminologia quineana, "postulados". Se estivermos dispostos a abdicar da idéia de que podemos identificar alguns não-postulados, [...] então nós podemos evitar a idéia de que alguns objetos são constituídos pela linguagem e outros não (grifos do autor).

O pensamento de Rorty, pautado no pragmatismo, é importante na discussão de tais elementos problemáticos, presentes inevitavelmente no contexto de toda produção de conhecimento. Contextualizar qualquer tipo de pensamento, prática 
investigativa ou mesmo intervenção é, nessa perspectiva, condição de possibilidade para a construção do próprio conhecimento. A noção de contexto pensada por Rorty aponta na direção da necessidade de se desconstruir qualquer configuração estática, essencial ou metafísica presente em algum tipo de pressuposto teórico. Para Rorty (1997), não há nada que preceda o contexto, bem como as condições sociais e históricas, sendo qualquer tipo de premissa já um postulado que produz ou (re)inventa algum tipo de realidade. Chauí (2006, p. 19), nessa linha, aponta:

[...] idéias que parecem resultar do puro esforço intelectual, de uma elaboração teórica objetiva e neutra, de puros conceitos nascidos da observação científica e da especulação metafísica, sem qualquer laço de dependência às condições sociais e históricas, são, na verdade, expressões dessas condições reais. Com tais idéias pretende-se explicar a realidade, sem se perceber que elas [idéias] precisam ser explicadas pela realidade social e histórica.

A referência aqui ao pensamento contextualizante e aintiessencialista de Rorty, diretamente relacionado a esse apontamento de Chauí, é elemento central para uma discussão crítica acerca do movimento nosográfico encerrado no diagnóstico depressivo. A questão depressiva se apresenta ainda hoje como um quadro clínico extremamente enigmático do ponto de vista clínico. Nesse âmbito, colocamos em perspectiva a posição aqui tomada a respeito da práxis investigativa que se pauta numa perspectiva pragmática no enfoque sobre a apreensão da realidade, a qual deve passar necessariamente pelo crivo da linguagem (Rorty, 1997).

Quando colocamos em questão, portanto, a pretensão purista da medicina na apreensão classificatória dos fenômenos depressivos, consideramos que a concepção de depressão, produzida e patrocinada pelos campos médico, científico, midiático e farmacológico, deve ser a primeira a ser problematizada no campo teórico- clínico, seja na psiquiatria, seja na psicologia, seja na psicanálise. Podemos afirmar que a medicina exerce uma prática ideológica quando descontextualiza o fenômeno denominado depressão e o toma como realidade independente do quadro subjetivo e mesmo cultural no qual ela se insere. ${ }^{8}$

\section{CONSIDERAÇÕES FINAIS}

Este trabalho preocupou-se especialmente em apontar os problemas do diagnóstico da depressão, e suas implicações no contexto das pesquisas médicas sobre o tema. Nessa busca, constata-se que a concepção de depressão na psiquiatria biológica é delineada pela circunscrição médica na aplicação de seu instrumental técnico. É importante salientar que, em contrapartida, autores como Verztman (2001) reverberam como fundamental para a apreensão e tratamento do sofrimento psíquico, o campo teórico e a experiência narrativa. Nessa direção, não estamos afirmando que toda psiquiatria pauta-se num reducionismo biológico e numa apreensão que toma a depressão como doença, síndrome ou transtorno. Há importantes campos da psiquiatria ligados à psicanálise, à fenomenologia e ao pragmatismo (Bezerra, 1999) que constituem modelos de concepção e tratamento que abarcam tanto o campo bioquímico quanto as dimensões psíquicas e sociais presentes na esfera do sofrimento subjetivo. Partindo desta concepção, acreditamos que o conceito da depressão aponta para um tipo de sofrimento ou arranjo sintomático que não deve ser negligenciado, mas deve ser investigado, levando-se em consideração a experiência subjetiva ali presente, dado que aparece na clínica contemporânea como manifestação que se distingue da melancolia?.

Poderíamos concluir essas considerações apontando cinco problemas cruciais que têm nos movido no sentido de uma apreensão mais apurada do sofrimento depressivo e sua relação com o campo subjetivo. São eles:

\footnotetext{
8 O termo "ideologia" é fundamentado por Marx (1867/1999) como aquilo que separa a produção das idéias das condições sociais e históricas nas quais elas são produzidas. Marx especifica tal caracterização afirmando que a ideologia é um mascaramento da realidade social, o qual permite a legitimação da exploração e da dominação. Em sua definição original, a ideologia se afirma no momento em que a realidade é tomada como natural, normal, a-histórica e aceitável.

9 Para um estudo sobre a distinção entre depressão e melancolia, ver Pinheiro (2005, p.101-109).
} 
a) A diluição da melancolia no campo da depressão;

b) A influência dos estudos biológicos e farmacológicos na construção do DSM-III e IV e do CID-9 e 10, que revelam a insustentabilidade $\mathrm{da}$ pretensão ateórica dos Manuais;

c) O reducionismo biológico pautado no cientificismo e na ideologia médica;

d) A exclusão da subjetividade na apreensão do sofrimento depressivo;

e) A concepção de transtorno, que coloca o sujeito em condição de silenciamento subjetivo e elimina da cena teóricoclínica a experiência narrativa singular.

Acredita-se relevantes esses pontos para o campo investigativo cuja apreensão leva em consideração a relação complexa do sujeito com sua própria história subjetiva.

\section{REFERÊNCIAS}

Associação de Psiquiatria Americana - APA. (1995). DSM-IV - Manual Diagnóstico e Estatístico de Transtornos Mentais. Porto Alegre: Artes Médicas.

Ballone, G. J. (2007). Fisiopatologia da depressão. Recuperado em 20 out. 2008, em http:// www.psiqweb.med.br/

Bezerra, B. (1999) A diversidade no campo psiquiátrico: Pluralidade ou fragmentação? Cadernos do IPUB, 14(1), 135-144.

Bogochvol, A. (2001). Sobre a psicofarmacologia. In M. C. R. Magalhães. (Org.). Psicofarmacologia e psicanálise (pp. 35-61). São Paulo: Escuta.

Clavreul, J. (1983). A ordem médica: Poder e impotência do discurso médico. São Paulo: Brasiliense.

Chauí, M. (2006). O que é ideologia. São Paulo: Brasiliense.

Ehrenberg, A. (1998). La fatigue d'être soi: Dépression et société. Paris: Odile Jacob.
Pinheiro, T. (2005). Depressão na contemporaneidade. Pulsional Revista de Psicanálise, 18(182), 101-109.

Organização Mundial de Saúde - OMS. (1948). CID06: Psiquiatria geral. Recuperado em 25 out. 2008, em http://www.psicologia.com.pt/instrumentos/dsm_cid

Organização Mundial de Saúde - OMS. (1978). CID09: Psiquiatria geral. Recuperado em 25 out. 2008, em http://www.psicologia.com.pt/instrumentos/dsm_cid

Organização Mundial de Saúde - OMS. (1995). CID10: Psiquiatria geral. Recuperado em 25 out. 2008, em http://www.psicologia.com.pt/instrumentos/dsm_cid

Rorty, R. (1997). Escritos filosóficos I: Objetivismo, relativismo e verdade. Rio de Janeiro: Relume Dumará.

Rodrigues, M. J. S. F. (2000). O diagnóstico da depressão. Psicologia USP, 11(1), Recuperado em 20 out. 2008, em http://www.scielo.br.

Sonenreich, C. Kerr-Corrêa, F., \& Estevão, G. (1991). Debates sobre o conceito de doenças afetivas. São Paulo: Manole.

Verztman, J. (1995). Tristeza e depressão. Rio de Janeiro: Vozes.

Verztman, J. (2001). A relevância da psicanálise na melancolia. Arquivos Brasileiros de Neurologia, Psiquiatria e Medicina Legal, 96(76), 36-41.

Wikipédia. (2006). Antidepressivo. Recuperado em 20 out. 2008, em http://pt.wikipedia.org/wiki/ Antidepressivo

Lacan, J. (1985). O Seminário, Livro 17: O avesso da psicanálise. Rio de Janeiro: Zahar. 